\title{
GAS CHROMATOGRAPHY-MASS SPECTROMETRY ANALYSIS AND IN VITRO ANTIMICROBIAL SCREENING OF WEDELIA GLAUCA (ORTEGA) O. HOFFM. EX HICKEN
}

\author{
KRISHNAVIGNESH L ${ }^{1 *}$, MAHALAKSHMIPRIYA A ${ }^{2}$, RAMESH M ${ }^{3}$ \\ ${ }^{1}$ Department of Embryology, Chennai Fertility Center and Research Institute, Chennai, Tamil Nadu, India. ${ }^{2}$ Department of Botany, \\ Government Arts College, Coimbatore, Tamil Nadu, India. ${ }^{3}$ Department of Biotechnology, Sri Ramakrishna College of Arts and Science, \\ Coimbatore, Tamil Nadu, India. Email: Krishnavignesh.l@gmail.com
}

Received: 11 June 2017, Revised and Accepted: 15 July 2017

ABSTRACT

Objective: Continued resistance toward the antibiotics urges us to explore newer antibiotics. Plants are being the safer source of antibiotics with lesser or no side effects. This study was designed to study the presence of phytochemical constituents and antibacterial activity of leaf and flower extracts of Wedelia glauca against urinary tract infection causing pathogens.

Methods: The plant leaves were extracted with five different solvents based on the polarity. The extraction was done using soxhalation. Antimicrobial activity was determined by agar well diffusion method for both the sample and standard. The acetone plant extract was subjected to gas chromatography-mass spectrometry (GC-MS) analysis for screening phytoconstituents.

Results: Preliminary phytochemical screening revealed the presence of diverse phytoconstituents in the plant. The different extracts exhibited a considerable antimicrobial potential. Among the solvents used acetone extract showed comparably better antimicrobial activity with $100 \%$ of inhibition rate with the maximum zone of inhibition of $1.6 \pm 0.77 \mathrm{~mm}$ against Staphylococcus sp. and Aspergillus sp. at the concentration of $5 \mathrm{mg}$. GC-MS analysis provided 8 major peaks which revealed the existence of a variety of bioactive compounds which may attribute to the efficacy of the plant.

Conclusion: W. glauca leaf and flower extracts displayed a broad spectrum of antibacterial and antifungal activity and can be considered as a potential source of newer antibiotic compounds.

Keywords: Wedelia glauca, Urinary tract infections, Antimicrobial resistance, Antibacterial, Antifungal, Soxhalation, Phytochemical analysis, Chromatography-mass spectrometry.

(C) 2017 The Authors. Published by Innovare Academic Sciences Pvt Ltd. This is an open access article under the CC BY license (http://creativecommons. org/licenses/by/4. 0/) DOI: http://dx.doi.org/10.22159/ajpcr.2017.v10i11.20557

\section{INTRODUCTION}

Among the most common infectious diseases, urinary tract infections (UTIs) are commonly encountered diseases by clinicians in developing countries with an estimated annual global incidence of at least 250 million [1,2]. Antimicrobial resistance (AMR) to various classes of antimicrobials to uropathogens continues to be a major health problem in different parts of the world $[3,4]$. The rapid emergence of resistant bacteria is occurring worldwide, endangering the efficacy of antibiotics, which have transformed medicine and saved millions of lives [5]. Infectious diseases caused by AMR microbes and the treatment are the serious problems in the field of medical science today world over. The development of an alternative drug line to treat such infectious diseases is urgently required [6]. Developing world, especially the countries of Southeast Asia, Western and Central Africa, India, and Pakistan are the most vulnerable to various infectious pandemic diseases [7]. Increasing AMR among microbes caused the emergence of new resistant phenotypes and further caused the development of new antimicrobial compounds [8]. It is essential to investigate newer drugs with lesser resistance. Drugs derived from natural sources play a significant role in the prevention and treatment of human diseases. In many developing countries, traditional medicine is one of the primary health-care systems $[9,10]$.

Population rise, inadequate supply of drugs, prohibitive cost of treatments, side effects of several allopathic drugs, and development of resistance to currently used drugs for infectious diseases have led to increased emphasis on the use of plant materials as a source of medicines for a wide variety of human ailments [11]. The therapeutic potential of medicinal plants as a source of noble natural antioxidants and antimicrobial agents has been well recognized all across the globe [12]. Plants have unlimited ability to produce a wide variety of secondary metabolites most of which are aromatic compounds, including alkaloids, glycosides, terpenoids, saponins, steroids, flavonoids, tannins, quinones and coumarins [13] forming the basis of plant-derived antimicrobial compounds. Plant-derived antimicrobial substances are plant originated secondary metabolites and have great concern because of their antibiotic activity without conferring resistance $[14,15]$. Screening of various bioactive compounds from plants has to lead to the discovery of a new medicinal drug which has efficient protection and treatment roles against various diseases [16]. The medicinal plants are a rich source of the secondary metabolites such as alkaloids, glycosides, steroids, and flavonoids, which are a potential source of drugs. Nearly one-third of the pharmaceuticals are plant origin. As all the plants are able to synthesize a multitude of organic molecules/phytochemicals, they are referred to as "secondary metabolites" [17].

Wedelia glauca (Asteraceae) is an herbaceous, invasive, perennial plant native to South America, and widely distributed in Argentina, Chile, Uruguay, Paraguay, Bolivia, and Brazil. It was introduced in the Southeastern United States (Louisiana and Florida), where it has been described with the former name Pascalia glauca and also in Spain (provinces of Madrid and Valencia) [18]. Wedelia genus it is an interesting source of potential bioactive molecules, as iridoids compounds, flavonoids, diterpenoids derivatives, phytosteroids, with antioxidant, anti-inflammatory, antimicrobial, hepatoprotective activity, analgesic and antihistamine, anti-implantation, antiasthmatic activities, and anticancer activity [19]. In this study, an effort has been made to determine the significance of $W$. glauca on its richness in phytochemical constituents and its antibacterial and antifungal properties. 


\section{METHODS}

\section{Plant materials}

The plant material was collected from the regions of Coimbatore, Tamil Nadu, India, from September to November 2012. The sample was identified and authenticated by the Botanical Survey of India, Coimbatore, India. The authentication voucher no. - BSI/ SRC/5/23/2013-14/Tech/1461.

\section{Preparation of the crude extracts}

Well-grown healthy leaves and flowers of $W$. glauca plant were collected and shade-dried at room temperature for a week. It was homogenized to a fine powder and stored in an airtight glass container at $4^{\circ} \mathrm{C}$ until the further process. The extraction of the plant materials was carried out using a Soxhlet extractor. Based on the polarity the solvents were selected for the study. The solvent used were petroleum ether (PE), ethyl acetate (EA), acetone (A), ethanol (E), and aqueous (W) in the ratio 1:10 $(\mathrm{w} / \mathrm{v})$. Individual extraction was been performed. The extract liquid was subjected to rotary evaporation to remove the solvent. The semisolid extract obtained was stored in an airtight container at $4^{\circ} \mathrm{C}$ in the freezer for further use. The dried extract was exposed to ultraviolet (UV) light (200-400 nm) for $24 \mathrm{hrs}$ and checked frequently for sterility by streaking on nutrient agar plates. For antimicrobial activity, a volume of $50 \mathrm{mg}$ of the extract was dissolved in $1 \mathrm{ml}$ of $5 \%$ dimethyl sulfoxide (DMSO). It was sterilized by filtration using $0.22 \mu \mathrm{m}$ millipore filter [20].

\section{Phytochemical analysis}

The preliminary phytochemical analysis was carried out on the different extracts using standard procedures $[20,21]$ to identify the phytochemical constituents. They are:

- Detection of alkaloids: The extracts were treated with few drops of dilute $\mathrm{HCl}$ and filtered. The filtrate was tested with the following reagents:

- Dragendroff's reagent: The extract was dissolved in methanol and few drops of Dragendorff's reagent is added. Orange red precipitate shows the presence of alkaloids.

- Test for flavonoids: Extracts were treated with few drops of sodium hydroxide solution. Formation of intense yellow color, which becomes colorless on the addition of dilute acid, indicates the presence of flavonoids.

- Test for carbohydrates: Benedict's test: To $1 \mathrm{ml}$ of the filtrate, $5 \mathrm{ml}$ of Benedict's reagent were added. The mixture was heated; appearance of red precipitate indicated the presence of reducing sugars.

- Test for steroids: The extract was mixed with $2 \mathrm{ml}$ of chloroform and concentrated sulfuric acid was added sidewise. A red color produced in the lower chloroform layer indicated the presence of steroids.

- Test for terpenoids: About $5 \mathrm{ml}$ of extract was mixed in $2 \mathrm{ml}$ of chloroform, and concentrated sulfuric acid ( $3 \mathrm{ml}$ ) was carefully added to form a layer. A reddish brown coloration of the interface was formed to show positive results for the presence of terpenoids.

- Test for proteins: Millon's test: Small portion of the extract when mixed with $2 \mathrm{ml}$ of Millon's reagent, a white precipitate appeared which turned red on gentle heating that confirmed the presence of protein.

- Test for reducing sugar: Benedict's test: Mixed equal volume of Benedict's reagent and test solution in a test tube. Heated in a boiling water bath for 5-10 minutes. The solution appears green, yellow, or red depending on the reducing sugar present.

- Test for tannins: Small quantities of various extracts were taken separately in water and tested for the presence of tannins. The extract was treated with dilute $\mathrm{FeCl} 3$ solution. A blue dark green or violet color was obtained.

- Test for saponins: The extract was mixed with $5 \mathrm{ml}$ of distilled water in a test tube and it was shaken vigorously. The formation of stable foam was taken as an indication for the presence of saponins.

\section{Collection and maintenance of pathogens}

Nine pathogenic bacteria used for the study were Bacillus sp., Staphylococcus sp., Klebsiella sp., Pseudomonas sp., Proteus sp.,
Escherichia coli, Streptococcus sp., Enterobacter sp., and Citrobacter sp., and the two fungal cultures were Candida albicans and Aspergillus sp. isolated from patients had been collected from "Sri Ramakrishna Hospital," Coimbatore, and maintained on nutrient agar slants, blood agar slants, and sabouraud dextrose agar (SDA) slants in cold room at $4^{\circ} \mathrm{C}$.

\section{Culture media}

Mueller-Hinton agar (MHA) and SDA were prepared according to the manufacturer's instruction, autoclaved and dispensed at $20 \mathrm{ml}$ per plate in Petri dishes. Set plates were incubated overnight to ensure sterility before use [20].

\section{Antibacterial assay}

Using the well diffusion method, 24-hrs broth culture of the respective bacteria was adjusted to a turbidity of $0.5 \mathrm{McF}$ arland standards. In brief, $0.2 \mathrm{ml}$ broth culture of the respective bacterial strain was dispensed into a $20 \mathrm{ml}$ sterile nutrient broth and incubated for $24 \mathrm{hrs}$ at $37^{\circ} \mathrm{C}$ and standardized at $1.5 \times 106 \mathrm{CFU} / \mathrm{ml}$ by adjusting the optical density to 0.1 at $600 \mathrm{~nm}$ and performed on UV/visible - spectrophotometer. Each of this bacterial culture was swabbed over sterile MHA plates separately using sterile cotton swabs. A well with diameter $6 \mathrm{~mm}$ was made using sterile cork borer. The bottoms of the wells were sealed by pouring 20-50 $\mu \mathrm{l}$ of molten MHA into the scooped out wells. Subsequently, from the prepared extract in DMSO, $100 \mu \mathrm{l}$ was added to the each well, final concentration was made up to $1,2,3,4$, and $5 \mathrm{mg}$, respectively. The plates were kept at $4^{\circ} \mathrm{C}$ for $1 \mathrm{hr}$ for the diffusion of extract, thereafter, the plates were incubated at $37^{\circ} \mathrm{C}$ for $24 \mathrm{hrs}$. Ampicillin (1 mg) was served as the positive reference standard to determine the sensitivity of the tested microbial strains. The antibacterial activity was determined by measuring the diameter of zones of inhibition $(\mathrm{mm})$ produced after incubation, and the results were expressed in millimeters ( $\mathrm{mm}$ ) [20].

\section{Antifungal study}

In vitro screening of antifungal activity was carried out against 2 pathogenic fungal strains using the agar well diffusion method. The culture of organisms was maintained on SDA. Activated cultures of fungal strains in Sabouraud's broth were adjusted to $1 \times 108 \mathrm{CFU} / \mathrm{ml}$ as per the McFarland standard. Each of the diluted cultures was swabbed on sterile SDA plates separately using sterile cotton swabs. The plate was dried for 30 minutes at room temperature. A well with diameter $6 \mathrm{~mm}$ was made using sterile cork borer. The bottoms of the wells were sealed by pouring 20-50 $\mu \mathrm{l}$ of molten SDA into the scooped out wells. From the prepared extracts in DMSO, $100 \mu \mathrm{l}$ was added to each well, the final concentration was made up to $1,2,3,4$, and $5 \mathrm{mg}$, respectively. Fluconazole (1 $\mathrm{mg}$ ) was used as the positive reference, and the plates were kept at $4^{\circ} \mathrm{C}$ for $1 \mathrm{hr}$ for the pre-diffusion of the extract. Then, the plates were incubated for $48-72 \mathrm{hrs}$ at $37^{\circ} \mathrm{C}$. The zone of inhibition of fungal growth was measured in diameter ( $\mathrm{mm}$ ) [20].

\section{Statistical analysis}

The data obtained after determining the zone of inhibition were recorded and mean and standard deviation was calculated. Data have been expressed as mean \pm standard deviation. Statistical analysis was performed with GraphPad Prism version 5 using ANOVA ( $p<0.0001$ is considered to be statistically significant).

\section{Gas chromatography-mass spectrometry (GC-MS) analysis}

GC-MS analysis of the acetone extract of the leaves and flower of W. glauca was carried out using thermo GC - trace ultraversion: 5.0 coupled with thermo MS DSQ II instrument. Compounds were separated on DB-35, MS capillary standard non-polar column (30 $\mathrm{m} \times 0.25 \mathrm{~mm})$, and film thickness $0.25 \mu \mathrm{m}$. Helium was used as the carrier gas at a constant flow of $1 \mathrm{ml} /$ minute and an injection volume of $1.0 \mu \mathrm{l}$, and the temperature programming was set with initial oven temperature at $70^{\circ} \mathrm{C}$ and held for 2 minutes and the temperature of the oven was raised to $260^{\circ} \mathrm{C}$ for 10 minutes and raised $6^{\circ} \mathrm{C} /$ minute and final temperature was $280^{\circ} \mathrm{C}$ for 10 minutes. Mass spectra were recorded over 50-650 (m/z) range. The components were identified by comparison of their mass spectra 
with those of mass spectral library, as well as by comparison of their retention time either with those of authentic compounds or with literature values.

\section{RESULTS AND DISCUSSION}

In the present study, the healthy leaves and flowers of $W$. glauca were collected, dried, and extracted with five different solvents, namely, PE, $\mathrm{EA}$, acetone, ethanol, and aqueous. Based on the polarity the solvents had been selected. Preliminary phytochemical analysis of the all five extracts revealed the presence of diverse phytochemical constituents which were observed and tabled (Table 1).

The discovery of antibiotics has revolutionized the management of infectious diseases more efficiently and timely. As by the famous saying, "Every invention and discovery has its own downside," the bacteria are developing resistance to those antibiotics, becoming recalcitrant, and troublemaker to treatment [22]. The emergence of multidrug resistance among the uropathogens and other microorganisms urge the researchers to identify newer antibiotics with zero side effects. This study examines the antimicrobial potential of $W$. glauca. All the assays had been performed in triplicates. The solvent DMSO (5\%) was used to dissolve the plant extracts. The activity of DMSO has also been studied as the negative control for all assays and showed no inhibition of microbial growth. The activity was examined based on the zone of inhibition produced around the wells and tabled (Tables 2-12), respectively.

Among the different extracts, acetone extract shown comparatively better activity than all other extracts. With this result, the acetone extract has been taken for further analysis in GC-MS. The results of the GC-MS analysis provided 8 major peaks (Fig. 1) which clearly indicate the presence of different phytochemical compounds. Based on the corresponding peaks, the top five compounds with higher probability have been noted (Table 13).

The objective of the study is to find the antimicrobial potential of leaf and flower extract of $W$. glauca against uropathogens. Further, to find out the bioactive principle behind the activity. The preliminary phytochemical analysis revealed the presence of important secondary metabolites from all five extracts of the plant. Collectively, it showed the presence of alkaloids, flavonoids, carbohydrates, proteins, amino acids, sterols, triterpenoids, tannins, and free sugar. There is a variation in the extraction of these phytochemical constituents by different solvents. This may be based on the polarity of the solvent and its extraction capacity. All of these secondary metabolites, making the plants a potential source of drugs. Medicinal plants represent rich sources

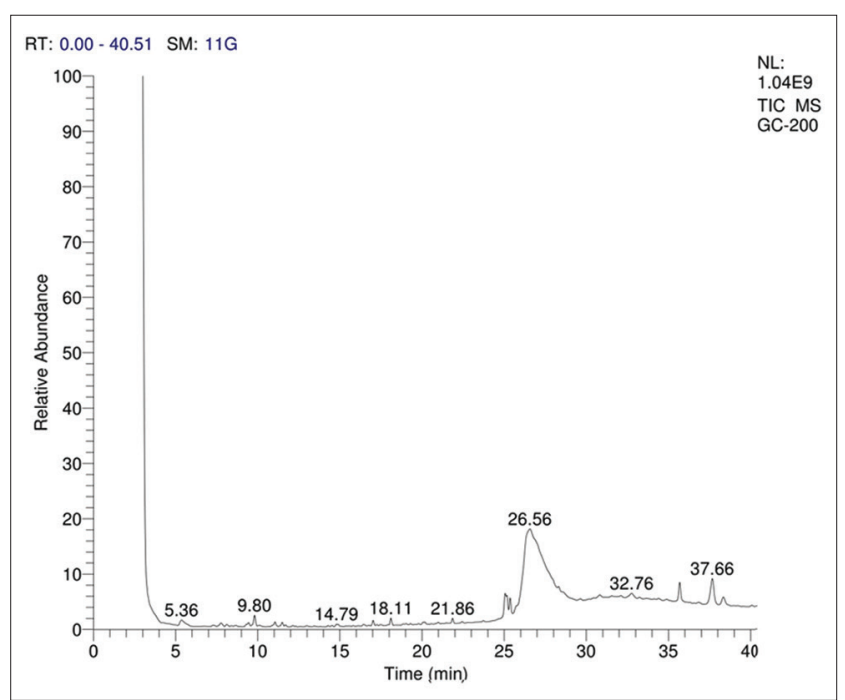

Fig. 1: The gas chromatography-mass spectrometry spectral peaks of acetone extract of Wedelia glauca of antimicrobial agents used medicinally in different countries and are a source of many potent drugs used in traditional medicine [23]. In this study, five different concentrations, they are 1, 2, 3, 4, and $5 \mathrm{mg}$, of the five extracts of $W$. glauca were analyzed. Each extract of five concentrations had been tested against nine bacteria, which included both Gram-positive and Gram-negative bacteria, and two fungal cultures. The results clearly revealed maximum zone inhibition in a dose-dependent manner. The tested bacterial strains showed a different pattern of inhibition. Among the two studied fungal cultures, ethanol and acetone showed better activity. Acetone extract shown higher activity against Aspergillus sp. with $1.6 \pm 0.77 \mathrm{~mm}$ and against Candida albicans with $1.5 \pm 0.22 \mathrm{~mm}$ of zone of inhibition. Although the zone of inhibition of the extracts is equal to the standard antibiotic, this study has shown that these extracts possess antifungal potential. Out of the nine bacterial cultures, Citrobacter sp., (Table 10) Enterobacter sp., (Table 9) and E. coli (Table 5) being more resistant toward the plant extracts as well as the standard antibiotic. Against these three organisms acetone extract exhibited higher activity with $1.3 \pm 1.00 \mathrm{~mm}$, $1.4 \pm 0.99 \mathrm{~mm}$, and $1.5 \pm 0.22 \mathrm{~mm}$ of zone of inhibition, respectively. While Bacillus sp. is susceptible all the extracts studied (Table 2). Against Bacillus sp. acetone extract has shown highest zone of inhibition with

Table 1: Preliminary phytochemical screening of different extracts of W. glauca

\begin{tabular}{llllll}
\hline \multirow{2}{*}{ Phytochemicals } & \multicolumn{3}{l}{ Plant extracts } & & \\
\cline { 2 - 6 } & PE & EA & A & E & W \\
\hline Alkaloids & - & + & + & + & - \\
Flavonoids & - & - & + & - & + \\
Carbohydrates & + & - & - & + & + \\
Proteins and amino acids & - & - & + & - & - \\
Steroids & + & - & + & - & + \\
Triterpenoids & + & - & + & - & + \\
Tannins & - & + & - & - & - \\
Reducing sugar & + & - & - & - & + \\
Saponins & + & + & + & + & + \\
\hline
\end{tabular}

+: Presence of the compound, -: Absence of the compound. PE: Petroleum ether,

EA: Ethyl acetate, A: Acetone, E: Ethanol, W: Aqueous, W. glauca: Wedelia glauca

Table 2: Antimicrobial activity of different extracts of $W$. glauca on Bacillius sp.

\begin{tabular}{llllll}
\hline $\begin{array}{l}\text { Extracts/ } \\
\text { standard } \\
\text { drug }\end{array}$ & $\mathbf{1} \mathbf{~ m g}$ & $\mathbf{2} \mathbf{~ m g}$ & $\mathbf{3} \mathbf{~} \mathbf{m g}$ & $\mathbf{4} \mathbf{~ m g}$ & $\mathbf{5} \mathbf{~ m g}$ \\
\hline $\mathrm{PE}$ & $0.9 \pm 0.57$ & $1.0 \pm 0.63$ & $1.1 \pm 0.77$ & $1.2 \pm 0.52$ & $1.3 \pm 1.00$ \\
$\mathrm{EA}$ & $1.1 \pm 0.77$ & $1.1 \pm 0.77$ & $1.2 \pm 0.52$ & $1.2 \pm 0.52$ & $1.3 \pm 1.00$ \\
$\mathrm{~A}$ & $0.9 \pm 0.57$ & $1.0 \pm 0.63$ & $0.9 \pm 0.57$ & $1.0 \pm 0.63$ & $1.4 \pm 0.99$ \\
$\mathrm{E}$ & $1.0 \pm 0.63$ & $1.2 \pm 0.52$ & $1.0 \pm 0.63$ & $1.0 \pm 0.63$ & $1.0 \pm 0.63$ \\
$\mathrm{~W}$ & $1.1 \pm 0.77$ & $1.1 \pm 0.77$ & $1.0 \pm 0.63$ & $1.1 \pm 0.77$ & $1.0 \pm 0.63$ \\
Ampicillin & $1.9 \pm 0.52$ & & & & \\
\hline W. glauca: Wedelia glauca, PE: Petroleum ether, EA: Ethyl acetate, A: Acetone, \\
E: Ethanol, W: Aqueous
\end{tabular}

Table 3: Antimicrobial activity of different extracts of W. glauca on Klebsiella sp.

\begin{tabular}{llllll}
\hline $\begin{array}{l}\text { Extracts/ } \\
\text { standard } \\
\text { drug }\end{array}$ & $\mathbf{1} \mathbf{~ m g}$ & $\mathbf{2} \mathbf{~ m g}$ & $\mathbf{3} \mathbf{~} \mathbf{g}$ & $\mathbf{4} \mathbf{~ m g}$ & $\mathbf{5} \mathbf{~ m g}$ \\
\hline PE & - & $1.1 \pm 0.77$ & $1.3 \pm 1.00$ & $1.0 \pm 0.63$ & $1.1 \pm 0.77$ \\
EA & - & $1.2 \pm 0.52$ & $1.3 \pm 1.00$ & $1.3 \pm 1.00$ & $1.1 \pm 0.77$ \\
A & $1.0 \pm 0.63$ & $1.2 \pm 0.52$ & $1.3 \pm 1.00$ & $1.1 \pm 0.77$ & $1.3 \pm 1.00$ \\
E & $1.3 \pm 1.00$ & $1.2 \pm 0.52$ & $1.3 \pm 1.00$ & $1.0 \pm 0.63$ & $1.1 \pm 0.77$ \\
W & $1.0 \pm 0.63$ & $1.0 \pm 0.63$ & $1.3 \pm 1.00$ & $1.1 \pm 0.77$ & $0.9 \pm 0.57$ \\
Ampicillin & $0.9 \pm 0.57$ & & & & \\
\hline
\end{tabular}

-: Indicates no zone of inhibition, W. glauca: Wedelia glauca, PE: Petroleum ether, EA: Ethyl acetate, A: Acetone, E: Ethanol, W: Aqueous 
$1.4 \pm 0.99 \mathrm{~mm}$. All the extracts with the minimum concentration of $1 \mathrm{mg}$ have exhibited inhibition effect on the organism. All the extracts shown good inhibition activity against Klebsiella sp., (Table 3) followed Proteus sp., (Table 4) and Staphylococcus sp. (Table 6). Against the above pathogens, maximum zone of inhibition was attained by acetone extract with $1.3 \pm 1.00 \mathrm{~mm}$, and aqueous extract with $1.3 \pm 1.00 \mathrm{~mm}$ and $1.6 \pm 0.77$, respectively. The plant extracts have inhibited the growth of Pseudomonas sp. (Table 8) considerably. Acetone extract shown higher

Table 4: Antimicrobial activity of different extracts of $W$. glauca on Proteus sp.

\begin{tabular}{llllll}
\hline $\begin{array}{l}\text { Extracts/ } \\
\text { standard } \\
\text { drug }\end{array}$ & $\mathbf{1} \mathbf{~ m g}$ & $\mathbf{2} \mathbf{~ m g}$ & $\mathbf{3} \mathbf{~ m g}$ & $\mathbf{4} \mathbf{~ m g}$ & $\mathbf{5} \mathbf{~ m g}$ \\
\hline $\mathrm{PE}$ & - & $1.0 \pm 0.63$ & $0.9 \pm 0.57$ & $0.9 \pm 0.57$ & $1.1 \pm 0.77$ \\
$\mathrm{EA}$ & - & $0.9 \pm 0.57$ & $1.2 \pm 0.52$ & $1.3 \pm 1.00$ & $1.1 \pm 0.77$ \\
$\mathrm{~A}$ & $1.1 \pm 0.77$ & $1.1 \pm 0.77$ & $1.2 \pm 0.52$ & $1.3 \pm 1.00$ & $1.2 \pm 0.52$ \\
$\mathrm{E}$ & $0.9 \pm 0.57$ & $1.0 \pm 0.63$ & $0.9 \pm 0.57$ & $1.3 \pm 1.00$ & $0.9 \pm 0.57$ \\
$\mathrm{~W}$ & - & - & $1.0 \pm 0.63$ & $1.3 \pm 1.00$ & $1.3 \pm 1.00$ \\
Ampicillin & $1.2 \pm 0.52$ & & & & \\
\hline
\end{tabular}

W. glauca: Wedelia glauca, PE: Petroleum ether, EA: Ethyl acetate, A: Acetone, E: Ethanol, W: Aqueous

Table 5: Antimicrobial activity of different extracts of W. glauca on E. coli

\begin{tabular}{lccccc}
\hline $\begin{array}{l}\text { Extracts/ } \\
\text { standard } \\
\text { drug }\end{array}$ & $\mathbf{1} \mathbf{~ m g}$ & $\mathbf{2} \mathbf{~ m g}$ & $\mathbf{3} \mathbf{~} \mathbf{m g}$ & $\mathbf{4} \mathbf{~ m g}$ & $\mathbf{5} \mathbf{~ m g}$ \\
\hline PE & & & & & \\
EA & - & - & - & - & $1.0 \pm 0.63$ \\
A & - & - & - & $1.1 \pm 0.77$ & $1.2 \pm 0.52$ \\
E & - & - & $1.0 \pm 0.63$ & $1.2 \pm 0.52$ & $1.3 \pm 1.00$ \\
W & - & - & - & $1.1 \pm 0.77$ & $1.2 \pm 0.52$ \\
Ampicillin & - & & & & \\
\hline
\end{tabular}

W. glauca: Wedelia glauca, PE: Petroleum ether, EA: Ethyl acetate, A: Acetone, E: Ethanol, W: Aqueous, E. coli: Escherichia coli

Table 6: Antimicrobial activity of different extracts of $W$. glauca on Staphylococcus sp.

\begin{tabular}{llllll}
\hline $\begin{array}{l}\text { Extracts/ } \\
\text { standard } \\
\text { drug }\end{array}$ & $\mathbf{1 ~} \mathbf{~ m g}$ & $\mathbf{2} \mathbf{~ m g}$ & $\mathbf{3 ~} \mathbf{~ g}$ & $\mathbf{4 ~} \mathbf{~ m g}$ & $\mathbf{5 ~} \mathbf{~ m g}$ \\
\hline $\mathrm{PE}$ & - & - & $1.0 \pm 0.63$ & $1.1 \pm 0.77$ & $1.2 \pm 0.52$ \\
$\mathrm{EA}$ & - & $1.1 \pm 0.77$ & $1.1 \pm 0.77$ & $1.3 \pm 1.00$ & $1.2 \pm 0.52$ \\
$\mathrm{~A}$ & $1.3 \pm 1.00$ & $1.1 \pm 0.77$ & $1.3 \pm 1.00$ & $1.3 \pm 1.00$ & $1.6 \pm 0.77$ \\
$\mathrm{E}$ & $1.0 \pm 0.63$ & $1.2 \pm 0.52$ & $1.2 \pm 0.52$ & $1.2 \pm 0.52$ & $1.2 \pm 0.52$ \\
$\mathrm{~W}$ & - & - & $1.0 \pm 0.63$ & $1.0 \pm 0.63$ & $1.6 \pm 0.77$ \\
Ampicillin & $1 \pm 0.63$ & & & & \\
\hline
\end{tabular}

W. glauca: Wedelia glauca, PE: Petroleum ether, EA: Ethyl acetate, A: Acetone, E: Ethanol, W: Aqueous

Table 7: Antimicrobial activity of different extracts of $W$. glauca on Streptococcus sp.

\begin{tabular}{llllll}
\hline $\begin{array}{l}\text { Extracts/ } \\
\text { standard } \\
\text { drug }\end{array}$ & $\mathbf{1} \mathbf{~ m g}$ & $\mathbf{2} \mathbf{~ m g}$ & $\mathbf{3} \mathbf{~ m g}$ & $\mathbf{4} \mathbf{~ m g}$ & $\mathbf{5} \mathbf{~ m g}$ \\
\hline PE & - & - & $0.9 \pm 0.57$ & $1.0 \pm 0.63$ & $1.1 \pm 0.77$ \\
EA & - & $1.1 \pm 0.77$ & $1.1 \pm 0.77$ & $1.1 \pm 0.77$ & $1.2 \pm 0.52$ \\
A & $1.1 \pm 0.77$ & $1.2 \pm 0.52$ & $1.3 \pm 1.00$ & $1.2 \pm 0.52$ & $1.2 \pm 0.52$ \\
E & $1.0 \pm 0.63$ & $1.1 \pm 0.77$ & $1.1 \pm 0.77$ & $1.2 \pm 0.52$ & $1.2 \pm 0.52$ \\
W & - & - & - & $1.2 \pm 0.52$ & $1.3 \pm 1.00$ \\
Ampicillin & $0.9 \pm 0.57$ & & & & \\
\hline
\end{tabular}

W. glauca: Wedelia glauca, PE: Petroleum ether, EA: Ethyl acetate, A: Acetone, E: Ethanol, W: Aqueous zone of inhibition with $1.4 \pm 0.99 \mathrm{~mm}$. From the results obtained, it is evident that this plant extracts showed a broad spectrum of activity against both Gram-positive and Gram-negative organisms. Among the five extracts investigated, acetone extract of the plant exhibited greater activity constantly against all the pathogens studied, it includes both bacterial cultures and fungal cultures. This activity may be due to the presence of secondary metabolites. Although all the extracts revealed the presence of different phytochemical constituents, the activity of acetone extract may be due to its ability in the extraction of

Table 8: Antimicrobial activity of different extracts of W. glauca on Pseudomonas sp.

\begin{tabular}{|c|c|c|c|c|c|}
\hline $\begin{array}{l}\text { Extracts/ } \\
\text { standard } \\
\text { drug }\end{array}$ & $1 \mathrm{mg}$ & $2 \mathrm{mg}$ & $3 \mathrm{mg}$ & $4 \mathrm{mg}$ & $5 \mathrm{mg}$ \\
\hline PE & - & $1.3 \pm 1.00$ & $0.9 \pm 0.57$ & $1.1 \pm 0.77$ & $1.3 \pm 1.00$ \\
\hline EA & - & $1.3 \pm 1.00$ & $1.1 \pm 0.77$ & $1.1 \pm 0.77$ & $1.2 \pm 0.52$ \\
\hline A & - & $0.9 \pm 0.57$ & $0.9 \pm 0.57$ & $1.2 \pm 0.52$ & $1.4 \pm 0.99$ \\
\hline $\mathrm{E}$ & - & $1.0 \pm 0.63$ & $1.1 \pm 0.77$ & $1.3 \pm 1.00$ & $1.3 \pm 1.00$ \\
\hline W & - & - & $0.9 \pm 0.57$ & $0.9 \pm 0.57$ & $1.0 \pm 0.63$ \\
\hline Ampicillin & - & & & & \\
\hline
\end{tabular}

Table 9: Antimicrobial activity of different extracts of $\boldsymbol{W}$. glauca on Enterobacter sp.

\begin{tabular}{llllll}
\hline $\begin{array}{l}\text { Extracts/ } \\
\text { standard } \\
\text { drug }\end{array}$ & $\mathbf{1} \mathbf{~ m g}$ & $\mathbf{2} \mathbf{~ m g}$ & $\mathbf{3} \mathbf{~} \mathbf{m g}$ & $\mathbf{4} \mathbf{~ m g}$ & $\mathbf{5} \mathbf{~ m g}$ \\
\hline PE & & & & & \\
EA & - & - & - & - & - \\
A & - & - & - & - & $1.2 \pm 0.52$ \\
E & - & - & - & $1.0 \pm 0.63$ & $1.4 \pm 0.99$ \\
W & - & - & - & - & - \\
Ampicillin & - & & & &
\end{tabular}

W. glauca: Wedelia glauca, PE: Petroleum ether, EA: Ethyl acetate, A: Acetone, E: Ethanol, W: Aqueous

Table 10: Antimicrobial activity of different extracts of W. glauca on Citrobacter sp.

\begin{tabular}{llllll}
\hline $\begin{array}{l}\text { Extracts/ } \\
\text { standard } \\
\text { drug }\end{array}$ & $\mathbf{1} \mathbf{~ m g}$ & $\mathbf{2} \mathbf{~ m g}$ & $\mathbf{3} \mathbf{~ m g}$ & $\mathbf{4} \mathbf{~ m g}$ & $\mathbf{5} \mathbf{~ m g}$ \\
\hline PE & & & & & \\
EA & - & - & - & - & $1.0 \pm 0.63$ \\
A & - & - & - & - & $1.1 \pm 0.77$ \\
E & - & - & - & $1.1 \pm 0.77$ & $1.3 \pm 1.00$ \\
W & - & - & - & - & $1.1 \pm 0.77$ \\
Ampicillin & - & - & - & - & - \\
\hline
\end{tabular}

W. glauca: Wedelia glauca, PE: Petroleum ether, EA: Ethyl acetate, A: Acetone, E: Ethanol, W: Aqueous

Table 11: Antimicrobial activity of different extracts of W. glauca on Aspergillus sp.

\begin{tabular}{lcclll}
\hline $\begin{array}{l}\text { Extracts/ } \\
\text { standard } \\
\text { drug }\end{array}$ & $\mathbf{1} \mathbf{~} \mathbf{m g}$ & $\mathbf{2} \mathbf{~ m g}$ & $\mathbf{3} \mathbf{~} \mathbf{g}$ & $\mathbf{4} \mathbf{~ m g}$ & $\mathbf{5} \mathbf{~ m g}$ \\
\hline PE & & & & & \\
EA & - & - & $0.9 \pm 0.57$ & $1.0 \pm 0.63$ & $1.3 \pm 1.00$ \\
A & - & - & $1.3 \pm 1.00$ & $1.0 \pm 0.63$ & $1.1 \pm 0.77$ \\
E & - & $0.9 \pm 0.57$ & $1.0 \pm 0.63$ & $1.1 \pm 0.77$ & $1.3 \pm 1.00$ \\
W & - & - & $1.0 \pm 0.63$ & $1.0 \pm 0.63$ & $1.1 \pm 0.77$ \\
Ampicillin & $2.2 \pm 0.77$ & & & & \\
\hline
\end{tabular}

W. glauca: Wedelia glauca, PE: Petroleum ether, EA: Ethyl acetate, A: Acetone, E: Ethanol, W: Aqueous 
large quantities of phytochemicals. A previous study has shown two possibilities that may account for the higher antibacterial activity of the extract are the nature of biologically active compounds (alkaloids,

Table 12: Antimicrobial activity of different extracts of W. glauca on Candida albicans

\begin{tabular}{llllll}
\hline $\begin{array}{l}\text { Extracts/ } \\
\text { standard } \\
\text { drug }\end{array}$ & $\mathbf{1} \mathbf{~ m g}$ & $\mathbf{2} \mathbf{~} \mathbf{m g}$ & $\mathbf{3} \mathbf{~} \mathbf{m g}$ & $\mathbf{4} \mathbf{~ m g}$ & $\mathbf{5} \mathbf{~ m g}$ \\
\hline PE & - & - & $0.9 \pm 0.57$ & $1.0 \pm 0.63$ & $1.2 \pm 0.52$ \\
EA & - & $1.0 \pm 0.63$ & $1.1 \pm 0.77$ & $1.3 \pm 1.00$ & $1.3 \pm 1.00$ \\
A & $0.9 \pm 0.57$ & $1.0 \pm 0.63$ & $1.0 \pm 0.63$ & $1.3 \pm 1.00$ & $1.5 \pm 0.22$ \\
E & - & $1.0 \pm 0.63$ & $0.9 \pm 0.57$ & $1.1 \pm 0.77$ & $1.3 \pm 1.00$ \\
W & - & - & $1.0 \pm 0.63$ & $1.1 \pm 0.77$ & $1.1 \pm 0.77$ \\
Fluconazole & $2.4 \pm 0.57$ & & & & \\
\hline
\end{tabular}

W. glauca: Wedelia glauca, PE: Petroleum ether, EA: Ethyl acetate, A: Acetone,

E: Ethanol, W: Aqueous flavonoids, tannins, triterpenoids which may be enhanced in the presence of the extract) and stronger extraction capacity of solvent that may yield a greater number of active constituents responsible for the antibacterial activity [24]. This may also be the reason for the higher bacterial and fungal activity shown by acetone extract. The acetone extract shown the presence of flavonoids. Flavonoids also play a major role in inhibiting microorganisms. A study claims that the flavonoids reported in the extract may be one of the major constituent responsible for registering the antibacterial activity. Flavonoids have been reported as a major class of natural products with anti-infective activity. Many research showed that the structure of flavonoids and antibacterial activity have a close relationship [25].

GC-MS analysis the presence of diverse phytoconstituents in the acetone extract of leaves and flowers of $W$. glauca. The library search list of the GC-MS shown the presence of compounds like c-Terpinene, 1-P-menthen-8-yl acetate, beta-phellandrene, á-Terpinyl acetate, 4,7,7-trimethylbicyclo[4.1.0]hept-4-en-3-ol, 4,4-dimethyl-cyclohex-

Table 13: GC-MS analysis of acetone extract of W. glauca

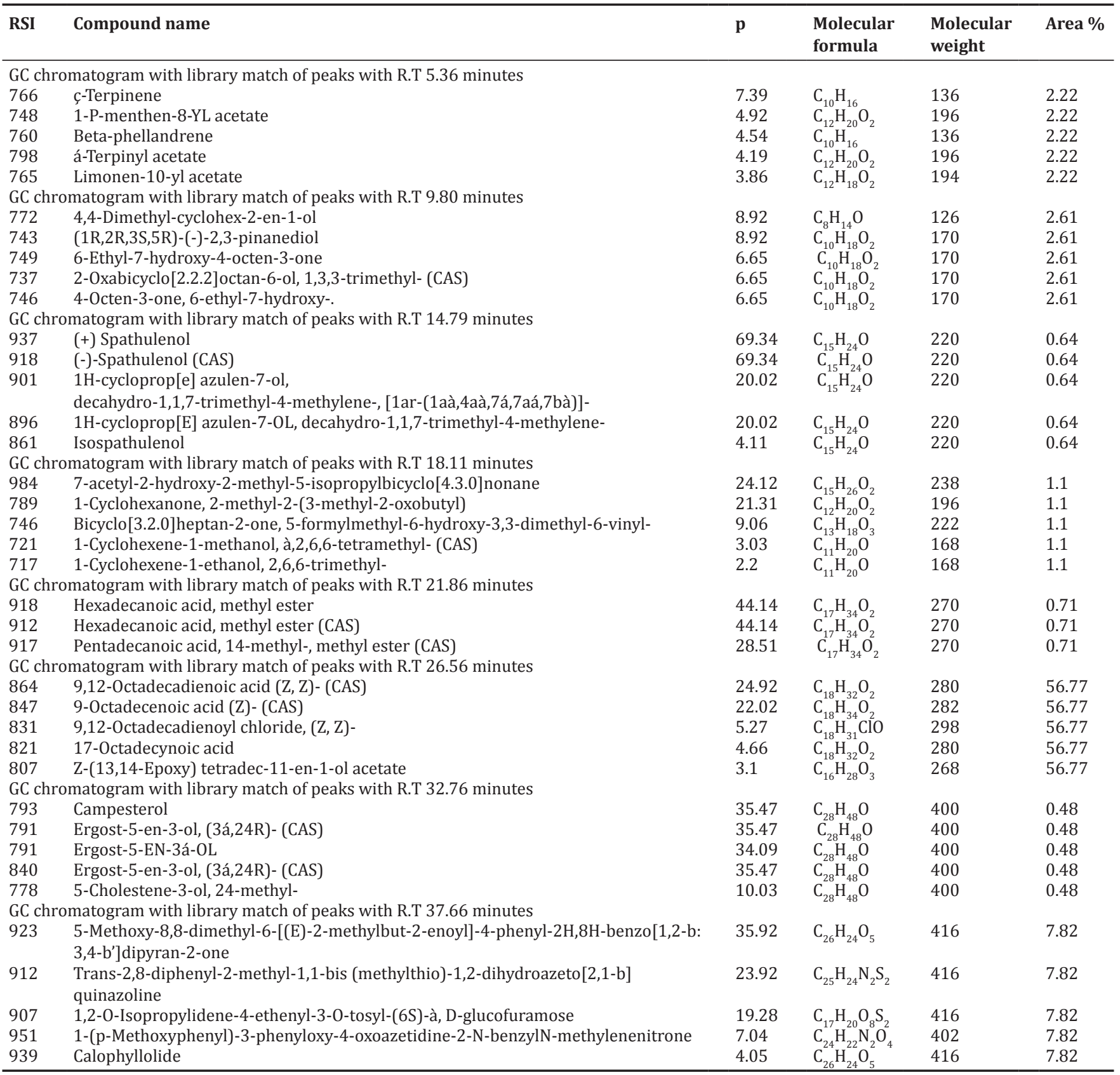

GC-MS: Gas chromatography-mass spectrometry, W. glauca: Wedelia glauca 
2-en-1-ol, (+) spathulenol, isospathulenol, 1-Cyclohexanone, 2-methyl-2-(3-methyl-2-oxobutyl), hexadecanoic acid, methyl ester, 9,12-octadecadienoic acid (Z,Z)- (CAS), 17-octadecynoic acid, campesterol, Ergost-5-EN-3á-OL, calophyllolide, and many more compounds shown (Table 13) is known to have higher potential in combating bacterial, fungal, and viral pathogens. Some of the compounds were reported for its anti-cancer property [26-28]. A previous review on genus Wedelia concluded that the thorough screening of literature available on genus Wedelia depicted the fact that it is a popular remedy among the various ethnic groups, Ayurvedic, and traditional practitioners for the treatment of ailments. Researchers are exploring the therapeutic potential of this plant as it has more therapeutic properties which are not known [19]. Through this present study, we explored the antibacterial and antifungal potential of W. glauca, by this, we can understand that this plant is also possessing higher potential in treating ailments, infections, and diseases like all the other species in the genus Wedelia. Further studies on the plant will definitely lead to the discovery of newer medications in the future.

\section{CONCLUSION}

The antimicrobial activity of $W$. glauca and nature of active principles present in the extracts of this plant is demonstrated for the first time against the pathogenic bacterial and fungal cultures. Among the different extracts studied acetone extract exhibited a better activity and revealed the presence of diverse secondary metabolites. GC-MS results of acetone extract clearly revealed the presence of various vital compounds which is responsible for the better activity of the plant. These results prove that this plant will be a promising source in the future research for the development of new antibiotic drugs for both bacterial and fungal infections.

\section{REFERENCES}

1. Ronald AR, Nicolle LE, Stamm E, Krieger J, Warren J, Schaeffer A, et al. Urinary tract infection in adults: Research priorities and strategies. Int J Antimicrob Agents 2001;17:343-8.

2. Barisic Z, Babic-Erceg A, Borzic E, Zoranic V, Kaliterna V, Carev M. Urinary tract infections in South Croatia: Aetiology and antimicrobial resistance. Int J Antimicrob Agents 2003;22 Suppl 2:61-4.

3. Oliveira FA, Paludo KS, Arend LN, Farah SM, Pedrosa FO, Souza EM, et al. Virulence characteristics and antimicrobial susceptibility of uropathogenic Escherichia coli strains. Genet Mol Res 2011;10(4):4114-25.

4. Farshad S, Ranjbar R, Japoni A, Hosseini M, Anvarinejad M, Mohammadzadegan R. Microbial susceptibility, virulence factors, and plasmid profiles of uropathogenic Escherichia coli strains isolated from children in Jahrom, Iran. Arch Iran Med 2012;15(5):312-6.

5. Golkar Z, Bagasra O, Pace DG. Bacteriophage therapy: A potential solution for the antibiotic resistance crisis. J Infect Dev Ctries 2014;8(2):129-36.

6. Srivastava J, Chandra H, Nautiyal AR, Kalra SJ. Antimicrobial resistance (AMR) and plant-derived antimicrobials (PDAms) as an alternative drug line to control infections 3 Biotech 2014;4(5):451-60.

7. Byarugaba DK. A view on antimicrobial resistance in developing countries and responsible risk factors. Int $\mathrm{J}$ Antimicrob Agents 2004;24(2):105-10.

8. Goossens H. The Chennai declaration on antimicrobial resistance in India. Lancet Infect Dis 2013;13(2):105-6.
9. Farnsworth NR. Ethno pharmacology and future drug development: The north American experience. J Ethnopharmacol 1993;38(2-3):145-52.

10. Houghton PJ. The role of plants in traditional medicine and current therapy. J Altern Complement Med 1995;1(2):131-43.

11. Ghurde MU, Malode SN. Phytochemical screening and assessment of biomolecules compounds in Scilla hyacinthina (Roth) Macbr. BULB. J Glob Biosci 2014;3(5):866-71.

12. Rawat S, Jugran AK, Bahukhandi A, Bahuguna A, Bhatt ID, Rawal RS, et al. Anti-oxidant and anti-microbial properties of some ethno-therapeutically important medicinal plants of Indian Himalayan region. Biotechnology 2016;6(2):154.

13. Das K, Tiwari RK, Shrivastava DK. Techniques for evaluation of medicinal plant products as antimicrobial agent: Current methods and future trends. J Med Plant Res 2010;4(2):104-11.

14. Baris O, Gulluce M, Sahin F, Ozer H, Kilic HH, Ozkan H, et al. Biological activities of the essential oil and methanolic extract of Achillea biebersteinii Afan. (Asteraceae). Turk J Biol 2006;30:65-73.

15. Palaniappan K, Holley RA. Use of natural antimicrobials to increase antibiotic susceptibility of drug resistant bacteria. Int J Food Microbiol 2010;140(2-3):164-8.

16. Govindappa M, Sravya SN, Poojashri MN, Sadananda TS, Chandrappa CP. Antimicrobial, antioxidant and in vitro anti-inflammatory activity of ethanol extract and active phytochemical screening of Wedelia trilobata (L.) Hitchc. J Pharmacogn Phytother 2011;3(3):43-51.

17. Vasanthi P, Ganapathy M, Evanjelene VK, Ayyavuv N, Angamuthu J. Phytochemical screening and antioxidant activity of extracts of the leaf and bark of Albizzia lebbeck (Benth). Acad J Med Plants 2014;2(2):26-31

18. Giannitti F, Margineda CA, Cid MS, Montobbio C, Soteras CI, Caffarena RD, et al. Fatal Wedelia glauca Intoxication in calves following natural exposure. Vet Pathol 2013;50(3):530-3.

19. Meena AK, Rao MM, Meena RP, Panda P. Pharmacological and phytochemical evidences for the plants of Wedelia genus-a review. Asian J Pharm Res 2011;1(1):7-12.

20. Krishnavignesh L, Mahalakshmipriya A, Ramesh M. In vitro analysis of phytochemical screening and antimicrobial activity of Parthenium hysterophorus L. Against pathogenic microorganisms. Asian J Pharm Clin Res 2013;6(5):41-4.

21. Anju V, Zachariah SM. Phytochemical screening, isolation, antibacterial and anticancer activity studies of Caesalpinia pulcherrima Linn leaves by HPTLC analysis. Int J Pharm Bio Sci 2017;8(2):12-29.

22. Divyashanthi CM, Adithiyakumar S, Bharathi N. Study of prevalence and antimicrobial susceptibility pattern of bacterial isolates in a tertiary care hospital. Int J Pharm Pharm Sci 2015;7(1):185-90.

23. Ferdioz J, Roy A. Antibacterial activity of aqueous alcoholic extract of Abutilon indicum aerial parts against Enterococcus faecalis-an in vitro study. Asian J Pharm Clin Res 2017;10(5):80-1.

24. Hidayathulla S, Chandra KK, Chandrashekar KR. Phytochemical evaluation and antibacterial activity of Pterospermum diversifolium blume. Int J Pharm Pharm Sci 2011;3(2):165-7.

25. Kota CS, Kumar H, Reddy MS. Activity of polyhedral extract against bacteria causing skin infections in diabetic patients. Asian J Pharm Clin Res 2017;10(5):147-9.

26. National Center for Biotechnology Information. PubChem BioAssay Database; AID=155. Available from: https://www.pubchem.ncbi.nlm. nih.gov/bioassay/155,

27. National Center for Biotechnology Information. PubChem BioAssay Database; $\mathrm{AID}=330$. Available from: https://www.pubchem.ncbi.nlm. nih.gov/bioassay/330.

28. Gilabert M, Ramos AN, Schiavone MM, Arena ME, Bardón A. Bioactive sesqui- and diterpenoids from the Argentine liverwort Porella chilensis. J Nat Prod 2011;74(4):574-9. 